\section{The Testimonios of System- Impacted Daughters of Color on Healing from Parental Incarceration}

\section{ANGIE BELEN MONREAL}

SHE, HER

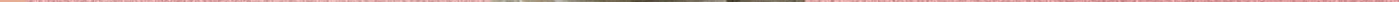




\section{THE TESTIMONIOS OF SYSTEM-IMPACTED DAUGHTERS OF COLOR ON HEALING FROM PARENTAL INCARCERATION}

\section{BACKGROUND}

Despite having $5 \%$ of the world's population, the United States currently holds over $25 \%$ of the world's incarcerated population, with 2.3 million people currently in jail or prison (American Civil Liberties Union [ACLU], 2020). Data shows that 52-63\% of individuals who are incarcerated have children, with the number of mothers rapidly increasing in recent years (Thomson et al., 2018). Nationwide, one in every 25 children currently has a parent incarcerated in jail or prison, and an estimated five to eight million children have experienced parental incarceration in their lifetime (Haskin \& Turney, 2018). Parental incarceration affects entire families, but children experience higher instances of trauma and adversity as a result of parental incarceration (Arditti \& Savla, 2015).

Children who have experienced the incarceration of a parent, family member, or community member are often referred to as being "system-impacted" (Cerda-Jara et al., 2019, p. 2). In this paper, "system-impacted" specifically refers to a child's experience of parental incarceration. This research focuses on female system-impacted children, referred to as daughters, because previous literature has demonstrated that daughters experience higher instances of antisocial behavior, anger, impulsivity, low self-esteem, and delinquency than sons as a result of parental incarceration (Burgess-Proctor et al., 2016). This research also focuses on system-impacted daughters of color because Black and Latinx parents are disproportionately represented in state and federal prison populations. For example, Black people make up 13\% of the U.S. population, but $40 \%$ of the incarcerated population (Sawyer \& Wagner, 2020). These numbers are a reflection of the disproportionate incarceration rates for the Black and Latinx populations (Western \& Pettit, 2010).

Current literature has found that parental incarceration has both short- and long-term negative effects on children (Miller, 2006). In the short term, system-impacted children experience traumatic separation, loneliness, unstable childcare arrangements, and the effects of reduced family income (Murray et al, 2012). In the long term, systemimpacted children are at higher risk of experiencing intergenerational incarceration, antisocial behavior, stigmatization, poor educational performance, and stress (Murrey, 2015), as well as general anger and additional mental health problems (Wakefield, 2007).

Existing research, largely based on quantitative analyses, fails to capture the voices of system-impacted children and the nuances of their unique experiences with parental incarceration. Academics have too often lumped all system-impacted children together when researching their experiences. For example, Burgess-Proctor et al. (2016) studied the effects of parental incarceration on both daughters and sons, but failed to analyze the impact of race and ethnicity on the lived experiences of both genders. It is important that an intersectional lens is applied to fully capture experiences of children with incarcerated parents. Testimonios are intended to capture the intersectional and nuanced experiences of system-impacted children with regard to gender, race, ethnicity, socioeconomic status, and so forth.

\section{RESEARCH QUESTIONS}

This paper focuses on the traumatic effects of parental incarceration on daughters of color and demonstrates how testimonios, a form of counter-storytelling, can be used as an effective healing tool. Conversations around parental incarceration are limited due to immense stigma and shame. Family members often tell children that their incarcerated parent is on vacation, rather than in jail or prison; however, children discover their parent's incarceration through other social means, such as friends (Burgess-Proctor et al., 2016). When children are told about the incarceration, they often proceed to conceal their parent's incarceration from friends and others (Burgess-Proctor et al., 2016) due to the stigmatization that will follow them into adulthood (Sykes \& Pettit, 2014). To counter the stigma and shame around parental incarceration, 
this research shed light on the following research questions:

1. How have daughters of color with incarcerated parents expressed themselves through storytelling?

2. Can counter-storytelling be used as an effective healing tool for daughters who have experienced parental incarceration?

Counter-storytelling is a framework used to elevate the voices of populations who are often forgotten and long silenced, making it an ideal method for addressing the needs of system-impacted daughters of color (Yosso, 2013). Counter-storytelling occurs when a person tells their life story or shares a particular experience, either informally in a conversation with another person or formally as a culturally responsive tool in a therapeutic setting. It has been found to be an effective tool for healing after trauma. For example, Native Americans who experienced forced boarding school reported emotional release and healing when sharing their stories through counter-storytelling (Charbonneau-Dahlen et al., 2016). Counter-storytelling promotes resiliency by showcasing how a person has adapted and built skills in order to overcome the systemic barriers and oppression they have faced (Hess, 2019). For instance, in response to an environment where there was an absence of nurturing roles in boarding schools, Native American fifth and sixth graders developed survival skills by becoming caregivers themselves for younger children. Most important, counter-storytelling shifts and challenges the white supremicist paradigm by illuminating patterns of racialized inequality through recounting experiences of individualized and shared racism (Yosso, 2013).

In this paper, Critical Race Theory (CRT) will be used in conjunction with counter-storytelling to elevate the voices of marginalized, underserved, and silenced system-impacted daughters of color. CRT is a theoretical framework used in the social sciences that examines the relationship between society and race, law, and power (Crenshaw et al., 1995). Using this framework will provide an in-depth look at how race and power impact populations who experience parental incarceration. CRT and counter-storytelling have been used in a variety of situations to help individuals heal from trauma and have been shown to acknowledge the resilience and survival skills of marginalized populations (Solorzano $\&$ Yosso, 2001). CRT is important for this research because most children who experience parental incarceration are people of color, creating an increase in future class and racial inequality through the negative consequences of mass incarceration on children (Wildeman \& Western, 2010).

Testimonios are used strategically to give agency to daughters of color. Agency gives people the power to negotiate their needs and identify what they feel in spaces of inequality (Cushing \& Lewis, 2009). This form of storytelling has been used in feminist research methodologies as a form of resistance, a tool for resilience building, and a source of hope in the midst of challenging systemic oppression (Huber \& Cueva, 2012). Testimonios decolonize storytelling by giving a person agency to highlight power and oppression, and can be viewed as a genre within counter-storytelling (Medina, 2018.).

\section{METHODOLOGY}

Previous research on the experiences of system-impacted children has reduced their experiences to statistics using quantitative methods. As such, through the practice of counter-storytelling with a CRT lens, this research provides a more in-depth representation of the experiences of system-impacted daughters of color. The qualitative data comes from in-depth interviews with two women who had incarcerated parents and one employee from Homeboy Industries' Legal Services department who had worked with the interviewees for over a year. Homeboy Industries, based in Los Angeles, CA, is a nonprofit organization that assists former gang members, previously incarcerated individuals, and their families to become positive contributing members of society through providing access to job placements, tattoo removals, therapy, and legal services (Leap et al., 2011). The organization is considered a good fit for this research because of their work with system-impacted families.

The women interviewed were from Los Angeles, CA, MexicanAmerican, in their late twenties, and both experienced the incarceration 
of their fathers when they were adolescents. Respondents were asked 18 questions during the interview about how they navigated their parent's incarceration, communicated with others, and what resources they deem necessary for healing. The interview questions include: "Looking back, how would you say being system-impacted affected your trajectory?"; "As of today, do you share your narrative of being system-impacted with others?"; "How do you feel when you talk about your mother's/ father's incarceration?"; and "What services do you feel are necessary for daughters to heal from parental incarceration?" The employee interviewed was asked different questions, such as, "In your role, do you experience listening to the children's narratives/stories about their experience with parental incarceration?" These questions were constructed ahead of the interview and were open-ended to promote discussion. Additional probing questions were asked during each interview when a respondent disclosed new information. For example, when an interviewee disclosed the impact her father's incarceration had on her career choice, she was asked to elaborate. Interviews were conducted in the Homeboy Industries legal office and recorded using a phone device and deleted soon after the interview was transcribed by the researcher.

All respondents were given consent forms and informed about the study's objective beforehand. Ethical measures were taken throughout the duration of the research project and pseudonyms are assigned to each respondent to maintain confidentiality. Before the interviews, the researcher built rapport with each interviewee through legal assistance and everyday interactions at Homeboy Industries. Furthermore, Columbia University Institutional Review Board (IRB) approved this research. The data from the semi-structured interviews were thematically transcribed and analyzed. Google Drive, Google Docs, and Microsoft Excel were used for coding and tracking emerging themes. After the data collection, thematic analysis was used to identify themes and patterns in responses.

106 | COLUMBIA SOCIAL WORK REVIEW, VOL. XIX

\section{RESULTS}

The objectives of using testimonios are to showcase the point of view of the person being interviewed, identify what they deem important from their experiences, and make an urgent call to action based on the themes and patterns that emerge from their intentional sharing (Reyes \& Rodirguez, 2012). Themes that arose across the interviews conducted in this study included a strong sense of healing from sharing testimonios, increased willingness to share, education as an escape, financial instability, and negative feelings towards individuals who did not share their struggle. In general, daughters of incarcerated parents found that telling stories of their lived experiences was a form of empowerment.

\section{INTERVIEW RESULTS}

\section{STRONG SENSE OF HEALING}

The Homeboy Industries' staff person who was interviewed reported observing a strong sense of healing from the women who shared their testimonios. Maria and Gabriela, who shared their testimonios, agreed and reported that sharing their narratives about their parent's incarceration with others was healing and therapeutic. A staff member who works in Homeboy Industries' Legal Services department focusing on family reunification, expungement, and other court services, stated:

[They share] all the little details that are important to them and half the time they end up crying. It is more like a therapy session. I only end up using half of...the stuff they have already told me. Half of it is not important to the case...but it is important for me to understand where they are coming from, so I can sort of better craft those declarations for a judge that is going to read. Yeah, a lot of times them doing their legal work ends up sort of being therapeutic sessions because they get to talk to someone who is not going to judge them, who is actually doing something to help them.

The themes in the interview reveal that storytelling and full disclosure about the traumatic experience of having a parent incarcerated can be therapeutic because the speaker is given a chance to share their own 
experiences and emotions regarding what occurred during this vulnerable part of their lives. The legal services staff stated that when women who are impacted by the criminal justice system are given the opportunity to speak about their experiences, they find it to be therapeutic and healing, especially because they are met with no judgement. For storytelling to work as an effective strategy, the speaker must have an attentive and encouraging listener (Rosenthal, 2003). Therefore, the professional staff at Homeboy Industries fulfilled this role by creating a judgment-free environment for her participants.

\section{AVOIDANCE BY PROFESSIONAL STAFF}

Avoidance has been observed in research on parental incarceration (McGinley \& Jones, 2018), as well as in this research. The employee interviewed discussed the prevalence of avoidance, or the staff member's reticence to speak of the client's parental incarceration unless they first broached the topic. When asked if she discusses with the children their experiences and feelings about having an incarcerated parent, the staff member responded, "Me no. Because the kids I usually see are five or under so they do not really understand what's going on. They will think their parents were on vacation or somewhere doing a work thing."

The professional staff usually avoids mentioning the incarceration of the children's parents, allowing the children to think that their parents are away on business or vacation. This is a relatively common experience for children as their parents, teachers, and service providers shield the child from the truth of what is really happening with their parents (BurgessProctor et al., 2016). This is often due to the parent's shame and guilt of being incarcerated and not wanting to inflict it on their children or not knowing how to address the topic in a way that is understandable for children. However, it is important for these children to grow up and begin to ask questions about their parents. Counter-storytelling can prove beneficial for this population as it speaks directly to these issues and gives voice to them, instead of perpetuating avoidance and secrecy.

\section{EDUCATION}

Within all three interviews, education was identified as a form of healing by both staff and the daughters. When asked what is necessary for system-impacted daughters to heal, Maria stated, "I would say education. Something they can be in control of [like] college degrees." She explained that by giving girls who are dealing with their parent's incarceration something they can control, like education, they begin to feel liberated. She recalled, "I would just be at the library, reading books, or learning stuff at school. It would take me to another place, a place where you don't need money."

\section{LONG-TERM FINANCIAL INSTABILITY}

Financial instability was another common theme. Both participants shared how their parent's incarceration led to a loss of family income and an increase in financial stress. It is important to acknowledge that in addition to the economic insecurity that exists while a parent is in prison, financial instability continues beyond release. The negative consequences of having a parent incarcerated do not disappear once they return home. Gabriela, who experienced her father's incarceration in middle and high school, reflected on her dad's experience after release: "He did not have a job for five years after that. So my mom was struggling for a long time. I feel like my dad's financial instability affected my mom and our household. So I could not go to college right after high school." Gabriela's father's unemployment and inability to contribute to the family's income affected her educational trajectory by limiting her ability to seek higher education. Both Maria and Gabriela mentioned struggling with food insecurity and paying bills, as well as needing additional assistance while their parents were incarcerated and in the years following.

\section{PRIVILEGE}

Another theme that emerged was anger that the daughters had towards others whom they identified as having "privilege," or those who they saw as not having any "real" problems. Through time, however, the 
anger transformed into a motivation to excel. Maria expressed, "At first, it made me a bit bitter because I would see people who do not have any real problems in life... but I grew out of that." She later explained that her bitterness about her parent's incarceration turned into motivation and increased her personal resilience. The concept of resilience appeared in both of the interviews, when Maria and Gabriela discussed how they came to understand and accept their parent's incarceration and use their adversity as motivation. Previous research has shown that children who experience separation and poverty due to a parent's incarceration experience lasting negative effects. However, through the use of external resources and strength-based factors, children can showcase resiliency (Miller, 2007). Resilience and healing may arise from the practice of storytelling.

\section{BENEFITS OF TESTIMONIOS}

By sharing their narratives, Maria and Gabriela were able to open up about what they felt when having to deal with their incarcerated parents. Although there were only two interviews with system-impacted daughters and one staff interview conducted, the data supported the predicted hypotheses. Testimonios are therapeutic for children of incarcerated parents, allow for a nuanced understanding of their experiences, and provide insight for service providers about the specific needs of the people they serve.

\section{LIMITATIONS}

One of the limitations of this research was limited time. Data collection was limited to less than ten weeks. There was not enough time to recruit a larger sample size of participants and it was difficult to create a strong bond with the participants in such a short period of time. Another limitation was the structure and sensibility of the interview. The interview was recorded on a device, creating an environment where interviewees felt reluctant about the amount of information they shared and skepticism about their privacy. A further limitation is that this research was conducted independently without team support.

\section{FUTURE DIRECTIONS}

This research highlighted the positive impacts of daughters of color sharing their testimonios. Because testimonio sharing was shown to be a source of empowerment, this research demonstrates a need for more safe spaces where daughters of color can feel comfortable sharing their testimonios, and in doing so, address their needs and emotions. Safe spaces can include a support group or an after-school program where youth with similar experiences of parental incarceration can get to know each other and feel less alone. These spaces can also provide an outlet for system-impacted children to understand their emotions and process the complexity of their anger. Social services organizations and social work practitioners should strive to create educational programs and support groups for system-impacted children of color.

Through the themes revealed in the interviews, this research points towards the specific needs of system-impacted daughters of color, including financial and educational resources. Without financial support of incarcerated parents, system-impacted children should have rental assistance, food pantries, and educational school supplies available. It is essential to create educational programs that serve this population, as those who experienced parental incarceration have demonstrated that they could be a potential escape. Given the findings of this research, future research with a larger sample size that includes women from other marginalized populations, in particular Black women, is needed to argue the effectiveness of storytelling in healing from parental incarceration.

\section{ACKNOWLEDGEMENTS}

I gratefully acknowledge the study participants for their willingness to share their experiences, as well as Homeboy Industries for making this research possible. Additionally, I want to acknowledge my family for their support, especially El Gerarchos Punk and Lula Munoz. I also want to thank Nayeli Monreal, Gerardo Monreal, Citlali Monreal from Anaheim, and Humberto. This research was supported by grants from the University of California, Los Angeles Advanced Academic Placement 
Program's Community Development and Social Justice (CDSJ), and the mentorship and guidance of Ms. Noemi Rivera-Olmedo and Dr. Alice

Ho.

\section{REFERENCES}

American Givil Liberties Union. (2020). Mass Incarceration. Retrieved from https:// www.aclu.org/issues/smart-justice/mass-incarceration

Arditti, A., \& Savla, J. (2015). Parental incarceration and child trauma symptoms in single caregivers homes. Journal of Child and Family Studies, 24(3), 551-561. https://doi. org/10.1007/s10826-013-9867-2

Burgess-Proctor, A., Huebner, B. M., \& Durso, J. M. (2016). Comparing the effects of maternal and paternal incarceration on adult daughters' and sons' criminal justice system involvement: A gendered pathways analysis. Criminal Justice and Behavior, 43(8), 1034-1055. https://doi.org/10.1177/0093854816643122

Castleberry, A., \& Nolen, A. (2018). Thematic analysis of qualitative research data: Is it as easy as it sounds? Currents in Pharmacy Teaching and Learning, 10(6), 807-815. https://doi.org/10.1016/j.cptl.2018.03.019

Cerda-Jara, M., Czifra, S., Galindo, A., Mason, J., Ricks, C., \& Zohrabi, A. (2019). Language Guide for Communicating About Those Involved In The Carceral System. Berkeley Underground Scholars Initiative. Retrieved from https:// undergroundscholars.berkeley.edu/blog/2019/3/6/language-guide-forcommunicating-about-those-involved-in-the-carceral-system

Cushing, P., \& Lewis, T. (2002). Negotiating mutuality and agency in care-giving relationships with women with intellectual disabilities. Hypatia, 17(3), 173-193. https://doi.org/10.1111/j.1527-2001.2002.tb00946.x

Charbonneau-Dahlen, B., Lowe, J., \& Morris, S. (2016). Giving voice to historical trauma through storytelling: The impact of boarding school experience on American Indians. Multicultural Perspectives of Intergenerational Transmission of Trauma, 25(6), 598617. https://doi.org/10.1080/10926771.2016.1157843

Crenshaw, K., Gotanda, N., Peller, G., \& Thomas, K. (1995). Critical race theory. The Key Writings that formed the Movement. New York. Retrieved from http:// ftp.gac.edu/ lwren/AmericanIdentititesArt $\% 20$ folder/AmericanIdentititesArt/ WhitenessProperty.pdf

Espino, M. M. (2008). Master narratives and counter-narratives: An analysis of Mexican American life stories of oppression and resistance along the journeys to the doctorate. Retrieved from https://repository.arizona.edu/handle/10150/195733

Haskins, A. R., \& Turney, K. (2018). The demographic landscape and sociological perspectives on parental incarceration and childhood inequality. American Psychological Association, 30(5), 341-357. https://doi.org/10.1037/0000062-002
Hess, J. (2019). Moving beyond resilience education: Musical counter-storytelling. Music Education Research, 21(5), 488-502. https://doi.org/10.1080/14613808.2019.1647 153

Huber, L. P., \& Cueva, B. M. (2012). Chicana/Latina testimonios on effects and responses to microaggressions. Equity \& Excellence in Education, 45(3), 392-410. https://doi.or g/10.1080/10665684.2012.698193

Kjellstrand, J. M., Reinke, W. M., \& Eddy, J. M. (2018). Children of incarcerated parents: Development of externalizing behaviors across adolescence. Children and Youth Services Review, 94, 628-635. https://doi.org/10.1016/j.childyouth.2018.09.003

Leap, J., Franke, T. M., Christie, C. A., \& Bonis, S. (2011). Nothing stops a bullet like a job: Homeboy industries gang prevention and intervention in Los Angeles. Beyond suppression: Global perspectives on Youth Violence, 127.

McGinley, M., \& Jones, C. (2018). Growing up with parental imprisonment: Children's experiences of managing stigma, secrecy and shame. Practice, 30(5), 341-357. https://doi.org/10.1080/09503153.2018.1450497

Medina, Cruz. (2018). Digital latin@ storytelling: Testimonio as Multi-modal Resistance. In C. Medina \& O. Pimentel (Eds.), Racial Shorthand: Coded Discrimination Contested in Social Media. Computers and Composition Digital Press. Retrieved from https://scholarcommons.scu.edu/engl/155/

Miller, K. M. (2007). Risk and resilience among African American children of incarcerated parents. Journal of Human Behavior in the Social Environment, 15(2-3), 25-37. https://doi.org/10.1300/J137v15n02_03

Miller, K. M. (2006). The impact of parental incarceration on children: An emerging need for effective interventions. Child and Adolescent Social Work Journal, 23(4), 472486. https://doi.org/10.1007/s10560-006-0065-6

Murrey, S. (2015). Alleviating risks of parental incarceration through mentorship (Publication no. 1652). [Doctoral dissertation, Walden University]. Retrieved from https://scholarworks.waldenu.edu/dissertations/1652/

Murray, J., Farrington, D., \& Sekol, I. (2012). Children's antisocial behavior, mental health, drug use, and educational performance after parental incarceration: A systematic review and meta-analysis. American Psychological Association, 138(2). 175210. doi:10.1037/a0026407

Reyes, K. B., \& Curry Rodríguez, J. E. (2012). Testimonio: Origins, terms, and resources. Equity \& Excellence in Education, 45(3), 525-538. https://doi.org/10.1080/1066568 4.2012.698571

Rosenthal, G. (2003). The healing effects of storytelling: On the conditions of curative storytelling in the context of research and counseling. Qualitative Inquiry, 9(6), 915933. https://doi.org/10.1177/1077800403254888 
Sawyer, W., \& Wagner, P. (2020). Mass incarceration: The whole pie 2020. Prison Policy Initiative, 24. Retrived from https://www.prisonpolicy.org/factsheets/pie2020_ allimages.pdf

Solorzano, D. G., \& Yosso, T. J. (2001). Critical race and LatCrit theory and method: Counter-storytelling. International Journal of Qualitative Studies in Education, 14(4), 471-495. https://doi.org/10.1080/09518390110063365

Sykes, B. L., \& Pettit, B. (2014). Mass incarceration, family complexity, and the reproduction of childhood disadvantage. The ANNALS of the American Academy of Political and Social Science, 654(1), 127-149. https://doi. org/10.1177/0002716214526345

Thomson, N. D., Kuay, H. S., Baron-Cohen, S., \& Towl, G. J. (2018). The impact of maternal incarceration on their daughter's empathy. International Journal of Law and Psychiatry, 56, 10-16. Retrieved from https://dro.dur.ac.uk/24178/1/24178.pdf

Wakefield, S. (2007). The consequences of incarceration for parents and children. University of Minnesota.

Western, B., \& Pettit, B. (2010). Incarceration \& social inequality. Daedalus, 139(3), 8-19. https://doi.org/10.1162/DAED_a_00019

Wildeman, C., Western, B. (2010). Incarceration in fragile families. The Future of Children, 20(2), 157-177. https://www.jstor.org/stable/20773699

Yosso, T. J. (2013). Critical race counterstories along the Chicana/Chicano educational pipeline. Routledge.
ANGIE BELEN MONREAL (she/her) is an incoming Ph.D. student in the sociology department at the University of California, Irvine. She will be graduating this year with a master of science in social work from Columbia University. Angie received her B.A. in sociology from the University of California, Los Angeles and her A.A. in sociology from Fullerton Community College. She has done hands on and research work on parental incarceration, reentry, and immigration. Angie is a proud first generation college student and was born and raised in Anaheim, CA. 